\title{
ANTI-PARKINSON POTENTIAL OF PERSEA AMERICANA SEED EXTRACTS THROUGH IN-SILICO DOCKING STUDY
}

\author{
RACHAEL EVANGELINE ${ }^{1}$, NIHAL AHMED ${ }^{2 *}$ \\ ${ }^{1}$ Department of Botany, St. Joseph's College (Autonomous), Bengaluru, Karnataka, India. ${ }^{2}$ Department of Life Sciences, Christ University, \\ Bengaluru, Karnataka, India. Email: rachaelrichard29@gmail.com
}

Received: 17 February 2020, Revised and Accepted: 21 March 2020

\section{ABSTRACT}

Objective: The aim of this study is to investigate the potential of Persea americana extracts for their Anti-Parkinson application through an in-silico docking study.

Methods: PubChem and protein data bank databases were used to retrieve 3D structures. AutoDock4 was used to perform protein-ligand docking analysis. PyMOL was used to visualize the docking results.

Results: Among the 30 ligand, the highest affinity was demonstrated by Hesperidin with a free binding energy of -6.8 kcal/mol and formation of five hydrogen bonds. The second highest significance was demonstrated by Biphenyl 4-(4-diethylaminobenzylidenamino) with a free binding energy of $-5.9 \mathrm{kcal} / \mathrm{mol}$ with the formation of 2 hydrogen bonds. Among the three sets of phytochemicals from different solvent extracts, water extract demonstrated the highest potential as Anti-Parkinson active.

Conclusion: P. americana extracts were analyzed for their Anti-Parkinson potential, and among the three extracts, the aqueous extract was predicted to have significant Anti-Parkinson potential, based on in silico docking analysis, due to the presence of active phytochemicals such as Hesperidin and others.

Keywords: Persea americana, Hesperidin, Protein-ligand docking, AutoDock 4, PyMOL.

(C) 2020 The Authors. Published by Innovare Academic Sciences Pvt Ltd. This is an open access article under the CC BY license (http://creativecommons. org/licenses/by/4. 0/) DOI: http://dx.doi.org/10.22159/ajpcr.2020.v13i5.37160

\section{INTRODUCTION}

The avocado (Persea americana) also termed as alligator bear or bitter fruit, with its origin in Mexico, Central, or South America ages back to 500 B.C $[1,2]$. Classified as a member of the flowering plant family Lauraceae, it has long been used as a traditional herbal medicine for the treatment of stomachache, diarrhea, hypertension, and diabetes [3]. A great source of Vitamin C, E, K, B6, riboflavin, niacin, folate, pantothenic acid, magnesium, potassium, lutein, beta-carotene, omega 3,6 , monounsaturated fatty acids, and phytonutrients such as stigmasterol and campesterol, carotenoids, flavonoids, and polyhydroxylated fatty alcohols [4,5] makes it a potential reducer of obesity, cardiovascular disease, and neurodegenerative diseases, respectively. Off lately, neurodegenerative disorders have affected millions of people worldwide, causing a mortality rate of 6.8 million per year [6]. Evidence suggests mitochondrial mutation and reactive oxygen species (ROS) being related to the pathogenesis for any neurological disorders [7], occurring due to the disruption in the balance between free radical formation and the counteractive endogenous antioxidant defense system that includes superoxide dismutase, catalase, and glutathione peroxidase [8-10]. The ROS so formed causes exponential oxidation of essential lipids and protein, resulting in genomic instability and telomere shortening [9-12]. It attacks the post-mitotic glial and neuronal cells contributing to cerebral ischemia, seizure disorders with an ultimatum of apoptosis. Diabetes induced neuropathy has also been involved in macrovascular disease, microangiopathy, cognitive decline, and brain atrophy $[13,14]$. Another key identified feature for any neurodegenerative disorders is the presence of Lewy bodies; these are proteinaceous deposits in nerve cells of the brain responsible for thinking and motor movement [15]. Amidst it, the alpha-synuclein protein has been a defined constituent responsible for synucleinopathies, Parkinson's disease, and dementia [16]. Although the protein has not been extensively studied, the recent consensus has shown alpha-synuclein to be associated with the modulation of dopamine release and promoting membrane curvature $[17,18]$.

In this context, traditional herbal products found in avocado have long been used to treat memory-related disorders. Neuronal cells require proper electrical impulses and gradient channels for their function which in turn depends on their fatty acid composition. Dietary consumption of avocado that's rich in linoleic acid and alphalinoleic acid-like fatty acids has proven to improvise membrane fluidity, synaptic plasticity, neural function, and neuroprotection [19]. Combinations of avocados and soybean fats have been shown to prevent oxidation and formation of ROS, elevating the flexibility of neuronal cells when exposed to low-oxygen conditions [20]. The polyphenolic and monounsaturated fatty acids found in avocado have been evident to inhibit fibril and Lewy body formation. Steroids in the form of stigmasterol, sitosterol, brassicasterol, and campesterol have also been shown to reduce amyloidogenic processing that may be advantageous in delaying the progression of Parkinson's disease [21,22]. In addition, the phenolic extracts of avocado seeds have been shown to have high levels of B-type procyanidins and epicatechin exhibiting antioxidant property that may serve the purpose of treating neurodegenerative disorders. It is also found to be rich in Vitamin E and unsaturated fatty acids preventing free radical damage mostly exhibited in such disorders. Rich in extracts such as peptone, B-galactoside, cytochrome P-450, polyuronoids, and volatile oils slow down the process of cellular aging and are anti-inflammatory in nature. Highly rich in amino acids, it is a great source of nutrients that might further aid in treating neurorelated disorders $[23,24]$. Therefore, the diversity of bio-nutrients and phytochemicals present in avocado plays an important role in the prevention and treatment of various degenerative disorders.

Previous docking studies have unraveled the antibacterial activity of ethanolic extracts of avocado where rutin present in it binds to 
PBP2a of the bacterial cell wall serving as an antibacterial drug [25]. Further in-vitro and in-silico studies have shown the hydroxyl group of proanthocyanidins in avocado chelating with the catalytic center of the enzyme tyrosine inhibiting its activity further laying a foundation in agriculture, food and nutrition industries [26]. With this context, this paper aims in taking an in-silico approach for understanding the interaction of various phytochemicals present in avocado to the oxidation pathways and amyloid formation in neurodegenerative Parkinson's disease; serving the possibility of therapeutics to treat it, respectively.

\section{METHODS}

The chemical structures of the phytochemicals identified from the extracts of $P$. americana were retrieved from the PubChem website (https://pubchem.ncbi.nlm.nih.gov/). The protein structure of alphasynuclein was retrieved from the protein data bank (PDB) website (www.rcsb.org) with a PDB ID: 1XQ8. The protein-ligand docking study was performed using AutoDock 4 software and the results are visualized using the PyMOL tool [27-32]

\section{RESULTS}

\section{Phytochemicals of $P$, americana}

Based on the previous study by Rachael et al. (2020) (unpublished data), the list of phytochemicals present in the ethanol, water, and ethyl acetate extract of $P$. americana seed was obtained and the chemical structures of these list of chemicals were retrieved from PubChem database. A total of 30 ligands were identified and retrieved from the PubChem database and were used for docking analysis.

\section{Anti-Parkinson's docking analysis}

The 30 ligand molecules were subjected to protein-ligand docking study to predict their Anti-Parkinson potential by inhibition of alpha-synuclein protein. AutoDock-4 was used for this purpose. The free binding energy of all the retrieved phytochemicals against the alpha-synuclein protein is tabulated in Table 1 . Among the 30 ligand molecules, the highest significance was exhibited by Hesperidin with a free binding energy of $-6.8 \mathrm{kcal} / \mathrm{mol}$ and formation of five hydrogen bonds (Lys-043, Lys-032, Val-040). The graphical representation of the interaction between Hesperidin and alpha-synuclein is shown in Fig. 1. The second highest significance was demonstrated by Biphenyl 4-(4-diethylaminobenzylidenamino) with a free binding energy of $-5.9 \mathrm{kcal} / \mathrm{mol}$ with the formation of 2 hydrogen bonds (Val-040, Lys-043). Interactions of Biphenyl 4-(4-diethylaminobenzylidenamino) with alpha-synuclein are shown in Fig. 2. The third highest significance was demonstrated by the aldosterone molecule with a free binding energy of $-5.8 \mathrm{kcal} / \mathrm{mol}$. The interaction between aldosterone and alphasynuclein is shown in Fig. 3. All three analyzed ligands show the same binding site interaction with the alpha-synuclein protein. Among the three extracts that are analyzed in this protein-ligand docking study, it is predicted that the aqueous extract of $P$. americana has the potential to be applied as an Anti-Parkinson agent, by inhibition of alpha-synuclein.

\section{DISCUSSION AND CONCLUSION}

Molecular docking is a frequently used approach in molecular drug designing, providing easy access to understand ligand-receptor interaction. Previous studies have shown these computation techniques to unravel and design potent new drugs by understanding the mechanism of drug-receptor interaction. Computer-aided drug design aids in recognizing small molecules by orienting and scoring them in the active binding site of the protein [33,34]. The protein alpha-synuclein has its active binding site for the formation of Lewy bodies and synucleinopathies. Three forms of extracts taken from P. americana were studied through docking for its potential binding affinity to the active site of the protein and inhibition of Synuclein activity. The highest significant value was evaluated for Hesperidin in the aqueous extract of the plant with a binding energy of $-6.8 \mathrm{kcal} / \mathrm{mol}$. It was found to be a more suitable ligand, confounding a greater ability to bind to the active site of the synuclein protein, thus preventing its aggregation and serving as a potential drug to treat Parkinson's. Moreover, previous reports have shown lower solubility of the drug

Table 1: The binding energy of phytochemicals from Persea americana with alpha-synuclein protein

\begin{tabular}{|c|c|c|c|}
\hline Extract & Compound name & Protein data bank ID & Binding energy (kcal/mol) \\
\hline \multirow[t]{7}{*}{ Ethanol extract } & Androsta-1,4-dien-3-one, 17-hydroxy-17-methyl- & 6300 & -5.7 \\
\hline & Isopropyl myristate & 8042 & -3.4 \\
\hline & Tricaprylin & 10850 & -3.3 \\
\hline & Glyceryl palmitate & 14900 & -3.1 \\
\hline & Benzene, 1,2,4-trimethyl-5-(3-methylbutyl) & 583850 & -4.7 \\
\hline & Retinal & 638015 & -5.4 \\
\hline & Methyl oleate & 5364509 & -3 \\
\hline \multirow{9}{*}{ Aqueous extract } & 1-Heptacosanol & 74822 & -3 \\
\hline & Aldosterone & 5839 & -5.8 \\
\hline & Biphenyl 4-(4-diethylaminobenzylidenamino) & 628682 & -5.9 \\
\hline & Hesperidin & 10621 & -6.8 \\
\hline & Methyl 14-methylpentadecanoate & 21205 & -3.1 \\
\hline & Octadecanoic acid & 5281 & -3.3 \\
\hline & Oleic acid & 445639 & -3.5 \\
\hline & Palmitic acid & 985 & -3 \\
\hline & Phorbol 12-myristate 13 -acetate & 27924 & -4.4 \\
\hline \multirow[t]{12}{*}{ Ethyl acetate extract } & 11,14-Eicosadienoic acid, methyl ester & 5365566 & -3.8 \\
\hline & 2,3,4-Trimethyl-5-hexen-3-ol & 141427 & -3.4 \\
\hline & Cyclohexane, 1-ethenyl-1-methyl-2,4-bis (1methylethenyl) & 641756 & -4.8 \\
\hline & Cyclopropanecarboxylic acid, pentadecyl ester & 560133 & -3.5 \\
\hline & Methacrylic acid, hexadecyl ester & 17235 & -3.5 \\
\hline & n-Dodecyl methacrylate & 8906 & -2.8 \\
\hline & n-Hexadecanoic acid & 985 & -2.9 \\
\hline & Octadecanoic acid & 5281 & -2.9 \\
\hline & Palmityl oleate & 5377655 & -2.8 \\
\hline & Saponarin & 441381 & -5.9 \\
\hline & Tridecanediol & 544162 & -3.5 \\
\hline & Z, Z-4,15-Octadecadien-1-ol acetate & 5363119 & -3.6 \\
\hline
\end{tabular}




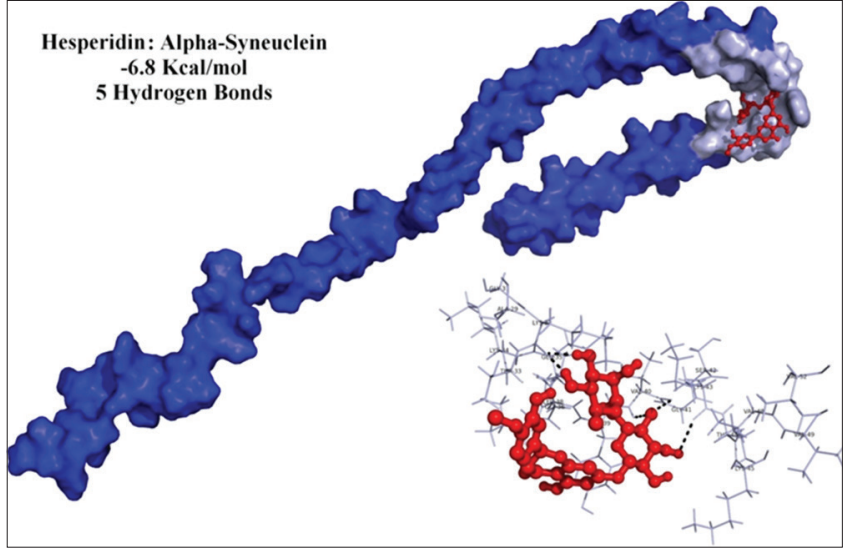

Fig. 1: Interaction between Hesperidin and alpha-synuclein

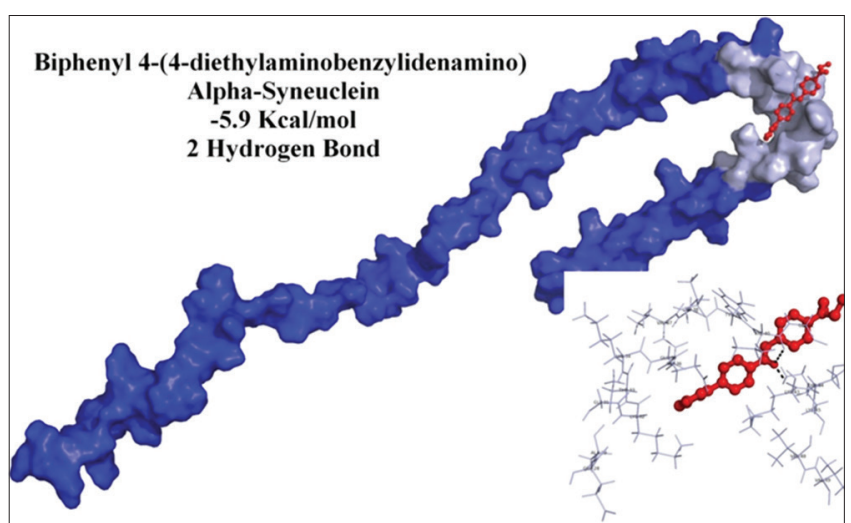

Fig. 2: Interaction between biphenyl

4-(4-diethylaminobenzylidenamino) and alpha-synuclein

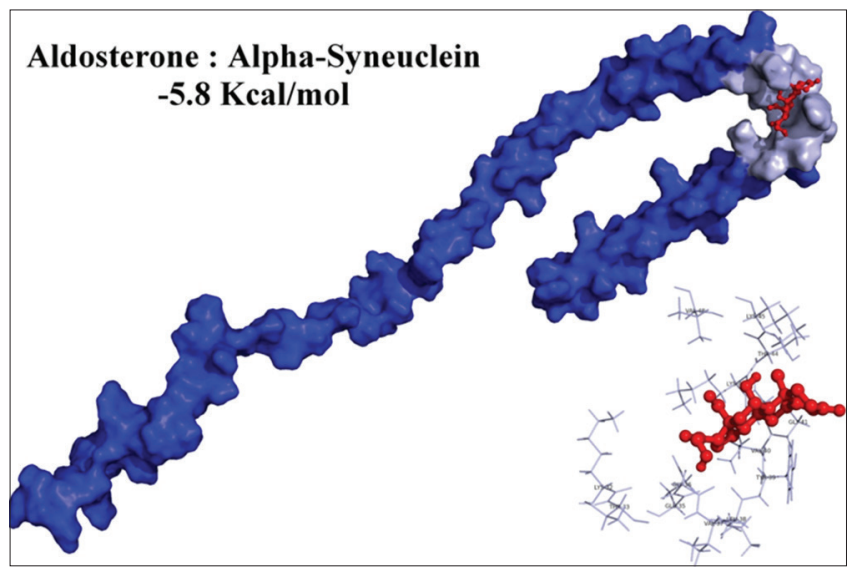

Fig. 3: Interaction between aldosterone and alpha-synuclein

being favorable towards good and complete oral absorption. Thus, in relation to the above context, aqueous extracts of $P$. americana are bound to have lower solubility index and Hesperidin being one of them makes it a potential candidate for a good and complete absorption for effective dosage [34]. Henceforth, this in-silico study has given us a comprehensive insight into the structure of the alpha-synuclein protein and the potential phytochemicals present in P. americana that could serve as a therapeutic drug to treat the neurodegenerative disorder.

\section{ACKNOWLEDGMENT}

The authors would like to thank the management of St. Joseph's College for supporting this work.

\section{AUTHORS' CONTRIBUTIONS}

All authors have contributed equally.

\section{CONFLICTS OF INTEREST}

No known conflicts of interest.

\section{AUTHORS' FUNDING}

No funding support for this current work.

\section{REFERENCES}

1. Rainey C, Affleck M, Bretschger K, Alfin-Slater RB. The California avocado: A new look. Nutr Today 1994;29:23-7.

2. Duester KC. Avocados a look beyond basic nutrition for one of nature's whole foods. Nutr Today 2000;35:151-7.

3. Yasir M, Das S, Kharya MD. The phytochemical and pharmacological profile of Persea americana mill. Pharmacogn Rev 2010;4:77.

4. Hasler CM, Bloch AS, Thomson CA, Enrione E, Manning C. Position of the American dietetic association: Functional foods. J Am Diet Assoc 2004; 104:814-26.

5. U.S. Department of Agriculture. Avocado, Almond, Pistachio and Walnut Composition. Washington, DC: U.S. Department of Agriculture: 2011.

6. World Health Organization. Neurological Disorders Affect Millions Globally: WHO Report. Brussels, Geneva: World Health Organization; 2007.

7. Toth C. Diabetes and neurodegeneration in the brain. In: Handbook of Clinical Neurology. Vol. 126. Netherlands: Elsevier; 2014. p. 489-511.

8. Mecocci P, Polidori MC, Ingegni T, Cherubini A, Chionne F, Cecchetti R, et al. Oxidative damage to DNA in lymphocytes from AD patients. Neurology 1998;51:1014-7.

9. Bresgen N, Karlhuber G, Krizbai I, Bauer H, Bauer HC, Eckl PM. Oxidative stress in cultured cerebral endothelial cells induces chromosomal aberrations, micronuclei, and apoptosis. J Neurosci Res 2003; 72:327-33

10. Petrozzi L, Lucetti C, Scarpato R, Gambaccini G, Trippi F, Bernardini S, et al. Cytogenetic alterations in lymphocytes of Alzheimer's disease and Parkinson's disease patients. Neurol Sci 2002;23:S97-8.

11. Migliore L, Fontana I, Trippi F, Colognato R, Coppede F, Tognoni G, et al. Oxidative DNA damage in peripheral leukocytes of mild cognitive impairment and AD patients. Neurobiol Aging 2005;26:567-73.

12. Nunomura A, Perry G, Aliev G, Hirai K, Takeda A, Balraj EK, et al. Oxidative damage is the earliest event in Alzheimer disease. J Neuropathol Exp Neurol 2001;60:759-67.

13. Alberti KG, Zimmet PZ. Definition, diagnosis and classification of diabetes mellitus and its complications. Part 1: Diagnosis and classification of diabetes mellitus. Provisional report of a WHO consultation. Diabet Med 1998;15:539-53.

14. Moreira PI, Oliveira CR. Mitochondria as potential targets in antidiabetic therapy. In: Diabetes-perspectives in Drug Therapy. Berlin, Germany: Springer; 2011. p. 331-56.

15. Neef D, Walling A. Dementia with lewy bodies: An emerging disease. Am Fam Physician 2006;73:1223-9.

16. Meade RM, Fairlie DP, Mason JM. Alpha-synuclein structure and Parkinson's disease-lessons and emerging principles. Mol Neurodegener 2019;14:29.

17. Chandra S, Chen X, Rizo J, Jahn R, Sudhof TC. A broken alpha-helix in folded alpha-synuclein. J Biol Chem 2003;278:15313-8.

18. Burré J, Sharma M, Tsetsenis T, Buchman V, Etherton MR, Südhof TC. Alpha-synuclein promotes SNARE-complex assembly in vivo and in vitro. Science 2010;329:1663-7.

19. Ceretta LB, Réus GZ, Rezin GT, Scaini G, Streck EL, Quevedo J. Brain energy metabolism parameters in an animal model of diabetes. Metab Brain Dis 2010;25:391-6.

20. Yehuda S, Rabinovitz S, Carasso RL, Mostofsky DI. The role of polyunsaturated fatty acids in restoring the aging neuronal membrane. Neurobiol Aging 2002;23:843-53.

21. Alzheimer Research UK. Reducing Your Risk of Dementia. Cambridge, United Kingdom: Alzheimer Research UK; 2017.

22. Ameer K. Avocado as a major dietary source of antioxidants and its preventive role in neurodegenerative diseases. In: The Benefits of Natural Products for Neurodegenerative Diseases. Berlin, Germany: Springer; 2016. p. 337-54

23. Ortega-Arellano HF, Jimenez-Del-Rio M, Velez-Pardo C. 
Neuroprotective effects of methanolic extract of avocado Persea americana (Var. Colinred) peel on paraquat-induced locomotor impairment, lipid peroxidation and shortage of life span in transgenic knockdown parkin Drosophila melanogaster. Neurochem Res 2019;44:1986-98.

24. Sarich C. After Reading This You'll Never Throw Out an Avocado Seed Again. Available from: http://www.themindunleashed.com/2017/04/ reading-youll-never-throw-avocado-seed.html.

25. Kusuma MT, Susilowati R. In silico study of avocado (Persea americana mill.) seed compounds against PBP2a receptor on Staphylococcus aureus. Bioinforma Biomed Res J 2018;1:45-8.

26. Chai WM, Wei MK, Wang R, Deng RG, Zou ZR, Peng YY. Avocado proanthocyanidins as a source of tyrosinase inhibitors: Structure characterization, inhibitory activity, and mechanism. J Agric Food Chem 2015;63:7381-7.

27. Ragunathan A, Ravi L. Molecular docking analysis of anticancerous interactions of salinomycin. J Chem Pharm Res 2015;7:352-7.

28. Vijayakumar S, Ragunathan A, Ravi L. Interactions of shikonin a potent antitumor drug with its known protein targets. Res J Life Sci
Bioinforma Pharm Chem Sci 2016;2:1-8.

29. Ravi L, Ragunathan A. Potential drug targets for aloin and microdontin: AN in silico analysis. Asian J Pharm Clin Res 2016;9:194-6.

30. Pisal P, Deodhar M, Kale A, Nigade G, Pawar S. Design, synthesis, docking studies and biological evaluation of 2-phenyl-3-(substituted benzo[d] thiazol-2-ylamino)-quinazoline-4(3h)-one derivatives as antimicrobial agents. Int J Pharm Pharm Sci 2018;10:57.

31. Miladiyah I, Jumina J, Haryana SM, Mustofa M. In silico molecular docking of xanthone derivatives as cyclooxygenase-2 inhibitor agents. Int J Pharm Pharm Sci 2017;9:98-104.

32. Rafiq Z, Sivaraj S, Vaidyanathan R. Computational docking and in silico analysis of potential efflux pump inhibitor punigratane. Int $\mathbf{J}$ Pharm Pharm Sci 2018;10:27-34.

33. Gupta E, Gupta SR, Kumar A, Kulshreshtha A, Ranjan R, Niraj K. Section: Biotechnology molecular docking study to identify potent inhibitors of alpha-synuclein aggregation of Parkinson' s disease. Int J Contemp Med Res 2019;6:5-12.

34. Jayaraj RL, Ranjani V, Manigandan K, Elangovan N. In silico docking studies to identify potent inhibitors of alpha-synuclein aggregation in parkinson disease. Asian J Pharm Clin Res 2013;6:127-31. 